\title{
ASSOCIATIVISMO LITERÁRIO, TRABALHO INTELECTUAL E O MERCADO DAS LETRAS NO SEGUNDO REINADO (1860-1882)
}

\author{
LITERARY ASSOCIATIONS, INTELLECTUAL LABOR AND PUBLISHING MARKETS \\ DURING THE SECOND REIGN (1860-1882)
}

Gabriela Nery*

\begin{abstract}
RESUMO
Este artigo investiga o associativismo literário que emergiu no Rio de Janeiro durante a vigência da lei no. 1083 de 1860, conhecida como "Lei dos Entraves". Para tanto, foram analisados os estatutos aprovados ou reformados durante a vigência dessa legislação e submetidos ao Conselho de Estado do Império. Dezesseis estatutos compuseram as fontes principais dessa pesquisa, num esforço de compreender como se constituin uma rede de associações voltadas ao mundo das letras em meados do século XIX. A partir disso, a análise se concentra no desenvolvimento de uma trama social, econômica e cultural que permitiu a expansão do trabalho intelectual, do crescimento do mercado das letras e da informação, além das iniciativas relacionadas à instrução. Esse processo foi fundamental à transformação das empresas jornalísticas a partir da década de 1880 e da expansão do mercado editorial no Rio de Janeiro do Segundo Reinado.
\end{abstract}

PALAVRAS-CHAVE: Associativismo literário. Imprensa. Mercado Editorial. Trabalho Intelectual.

\begin{abstract}
This article investigates the literary associations that emerged in Rio de Janeiro during the term of law no. 1083 of 1860, known as the "Lei dos Entraves". For that, sixteen statutes comprise the sources of this research, all of them approved by the Empire's State Council, in order to understand the process of consolidation of a network of associations dedicated to the literary world. Those societys were essential to foster the development of social, economic and cultural connections that allowed the expansion of intellectual labor and other initiatives related to education, publishing and journalistic markets. This process was also fundamental for the transformation of journalistic companies from the 1880s onwards and the expansion of circulation of press and print materials in Rio de Janeiro, during the Second Reign.
\end{abstract}

KEYWORDS: Intelectual Labor. Literary Associativism. Press. Publishing Market.

\section{A “LEI DOS ENTRAVES” NO CAMINHO DO ASSOCIATIVISMO LITERÁRIO}

Quando a sociedade Ensaios Literários submeteu seu estatuto ao crivo dos ministros do Conselho de Estado do Império, o modo de se associar no Brasil já não era o mesmo do ano anterior. Com a aprovação da lei no 1.083, de agosto de 1860, posteriormente apelidada "Lei dos Entraves", toda

\footnotetext{
* Professora da Rede Municipal de Ensino de São Paulo. Doutoranda em História pela Universidade Estadual de Campinas (Unicamp). E-mail: gabriela_nery@yahoo.com
} 
associação que pretendesse ganhar as ruas deveria submeter, obrigatoriamente, seus estatutos para a avaliação do colegiado. Na ocasião, a sociedade Ensaios Literários havia terminado a redação de suas normas no dia 7 de maio de 1861, tendo recebido aprovação da Seção de Negócios do Império do Conselho de Estado algumas semanas depois, a 17 de agosto. Houve apenas uma pequena ressalva, no artigo 82, em que os conselheiros solicitaram o acréscimo da frase: "Salvas as disposições das leis e regulamentos em vigor" (BRASIL, 1861, p. 386). Feito o adendo, os sócios poderiam reunir-se e pôr em curso seus interesses.

O Segundo Reinado sustentou um ritmo ascendente de fundação de associações tanto na Corte quanto nas províncias. Essa dinâmica deitava raízes da vinda da família real portuguesa para o Brasil, em 1808, ganhou corpo no Primeira Reinado e percorreu o período regencial, avançando sobre a década de 1840. Ela foi analisada por Manuel Duarte Moreira de Azevedo já no último quartel do século XIX e suas conclusões, consideradas o primeiro estudo sobre o associativismo brasileiro, apontavam para um processo de crescimento irregular, balizado pelas transformações políticas do Brasil oitocentista. Em 1884, o estudo de Moreira de Azevedo foi apresentado como "memória histórica" em uma sessão do Instituto Histórico e Geográfico Brasileiro, associação na qual o autor ocupava, então, o posto de $1^{\circ}$ secretário. No ano seguinte, o trabalho foi publicado na revista do IHGB sob o título de Sociedades fundadas no Brasil desde os tempos coloniais até o comeşo do atual reinado (AZEVEDO, 1885).

Ao pesquisar o associativismo beneficente no Brasil durante a vigência da "Lei dos Entraves", Marconni Marotta (2015) deu tratamento estatístico não apenas às informações trazidas no artigo de Moreira de Azevedo, mas também aos registros contidos em fontes bastante utilizadas nos estudos sobre o Brasil do século XIX, como o Almanak Laemmert. O autor fez uma extensa pesquisa e revelou que entre 1808 e 1840 fundaram-se 55 associações no país. Já entre 1840 e 1889 foram 887, um aumento de 1512,72\%. Desse número, Marotta afirma que 210 seriam sociedades pertencente ao grupo das literárias, científicas ou relacionadas à instrução pública, classificadas por ele em um mesmo conjunto, separandoas das associações beneficentes, das recreativas e desportivas, das industriais e das religiosas.

O autor, portanto, constituiu cinco categorias ajustadas aos seus objetivos de pesquisa - analisar aquelas que prestavam socorros mútuos - e subdividiu esse conjunto posteriormente. Dessa forma, naturalmente considerou organizações como a Sociedade Beneficente Artística e Literária do Brasil, de 1887, ou a Sociedade Honrosa, Beneficente e Literária dos amigos da Polônia, de 1848, como pertencentes ao espectro que mais lhe importava, a despeito de seu caráter literário. Como aqui os objetivos e objetos são outros - analisar as diversas sociedades que tomaram parte no mundo das letras a partir da segunda metade do século XIX - pode haver alguma dissonância, mas os números não deixam de ser reveladores sob ambos os aspectos. Assim, entre a sociedade Ensaios Literários, de 1861, e a Associação de auxílios mútuos dos empregados da Tipografia Nacional, de 1880, há um mundo a se percorrer dentro do associativismo no Segundo Reinado, com vistas àquelas que promoviam as belas letras e a instrução pública até as primeiras organizações de trabalhadores da imprensa. 
Há uma vasta historiografia que se debruça sobre o associativismo oitocentista, especialmente aquele que se desenvolveu a partir do ano de 1860, com a aprovação da "Lei dos Entraves". David Lacerda (2011) encontra-se nesse grupo historiográfico, mas não deixa de destacar que essa legislação viria para incidir diretamente sobre o contexto de dinamização e rearticulação das atividades mercantis, deflagradas na década anterior. O autor aponta que os anos de 1850 foram atravessados por uma série de debates e mudanças na vida econômica nacional, que entraram na ordem do dia da atividade legislativa da Corte. Assim, fecundou-se uma historiografia importante debruçada sobre os processos iniciados a partir dessa década, incluindo-se a área da história econômica, analisando as ações que buscavam regulamentar o comércio, as atividades das casas bancárias frente aos problemas de liquidez da economia, o que se ligava diretamente à política fiscal imperial.

Dentro dessa seara destacavam-se os debates sobre o controle da emissão de meios circulantes, sobre a presença maciça de moedas fiduciárias no mercado interno, além das dificuldades de expansão de crédito, da busca por dirimir a especulação financeira na bolsa de valores e o descompasso entre a situação econômica da Corte e das províncias (SÁENZ, 2011; GAMBI, 2012; LEVY, 1994). A "Lei dos Entraves", dessa maneira, fora formulada e aprovada para agir de forma restritiva, normativa e centralizadora sobre essas demandas, recaindo sobretudo no funcionamento das sociedades anônimas e comanditárias de caráter mercantil. Entretanto, o escopo da norma acabou por alcançar outras associações em muito distantes das atividades bancárias ou de crédito. Essa ingerência estatal sobre organizações civis que se dedicavam a diversos temas revelava, de acordo com Lacerda, não um suposto efeito secundário, mas sim o interesse direto do Estado Imperial em controlar as atividades das associações.

O projeto político-econômico expresso na "Lei dos Entraves" de 1860, portanto, expunha um contexto fundamental para a compreensão do associativismo na segunda metade do século XIX. Há inclusive uma importante convergência historiográfica que indica a relação direta do desenvolvimento das atividades urbanas e expansão demográfica nas cidades com o associativismo do período. ${ }^{1}$ De todo modo, isso não implica dizer que os modos de se associar no Brasil não tenham se desenvolvido sob outros contextos e formas diversas, como no caso das irmandades e das corporações de ofício, essa última proibida no Brasil a partir da Constituição de 1824. Assim, olhar para essas questões demanda uma análise multifacetada, que pode ser empreendida destacando-se três momentos: do Código Comercial de 1850 à legislação aprovada em 1860 - e seus desdobramentos sobre as associações até 1882, quando a "Lei dos Entraves" é revogada.

Maria Bárbara Levy (1994) acompanhou esse movimento ao analisar a formação das sociedades anônimas no Brasil - objeto da nova legislação - indicando ao menos cinco fatores, importantes do ponto de vista da condução da política econômica do Império, que pavimentaram parte desse caminho. A primeira residia na aprovação da tarifa Alves Branco em 1844; posteriormente, a reforma monetária

${ }^{1}$ Cf. Batalha (1999, 2003 e 2010), Jesus (2007), Jesus; Lacerda (2010), Lacerda (2011), Viscardi (2008, 2009) e Luca (1990). 
ocorrida em 1846; e, para ano de 1850, a abolição do tráfico transatlântico de escravizados, a promulgação da Lei de Terras e a aprovação do primeiro Código Comercial do Império. Em conjunto, essas ações tiveram grande impacto no desenvolvimento da economia urbana, especialmente no Rio de Janeiro. ${ }^{2}$

É especialmente importante para essa análise se deter na aprovação do Código Comercial. Ele veio regulamentar e potencializar a atividade mercantil no Brasil, criando uma legislação própria e inédita, que possibilitava, juridicamente, a constituição de sociedades anônimas e comanditárias. ${ }^{3}$ Levy (1994) afirma que este foi um marco na questão do direito à propriedade, porque permitiu a associação de capitais disponíveis no mercado para promover uma expansão da produção até então sem precedentes - caducando o modelo baseado no capital individual. Esse formato movimentou a praça do Rio de Janeiro, e o pregão da Bolsa de Valores da cidade havia percebido o aumento das transações na ordem de $460 \%$ entre 1850 e 1852. Ainda nesse sentido, se em 1850 havia apenas cinco empresas cotadas na Bolsa, em 1855 eram 16, e 76 companhias anônimas e 515 sociedades comanditárias tinham sido inscritas no Tribunal do Comércio do Rio de Janeiro, até o ano de 1865 (GODOI, 2014).

É importante destacar que a atividade cultural que fervilhava nas ruas, nos cafés, nos teatros, nos bares ou nas redações de periódicos acompanhava a movimentação da praça comercial. Em um cenário urbano em expansão, engendravam-se múltiplas iniciativas e redes de sociabilidades dentre os homens de letras, que não deixaram de fundar suas próprias sociedades como forma de colocar seus projetos e anseios em prática - e acabaram submetidos à "Lei dos Entraves". Dessa forma, os que tivessem desejo de constituir qualquer tipo de associação deveriam se dirigir, primeiramente, à delegacia mais próxima do lugar onde pretendessem tomar as reuniões, para pleitearem autorização. Uma vez autorizados, poderiam se reunir quantas vezes julgassem necessário para elaboração dos estatutos e só então deveriam remetê-los à Seção de Negócios do Império do Conselho de Estado. Junto a eles, também deveriam ser submetidas as atas das reuniões para deferimento. Qualquer mudança nas normas deveria novamente ser posta ao crivo dos conselheiros (MAROTTA, 2015).

\section{AS ASSOCIAÇÕES LITERÁRIAS NAS BASES DO TRABALHO INTELECTUAL E DO MERCADO DAS LETRAS}

Foi dessa maneira, percorrendo esse trâmite, que a sociedade Ensaios Literários começou a funcionar a partir de 1861. Em seus estatutos, constava que ela teria como fim o desenvolvimento intelectual de seus associados, facilitando-lhes os estudos. Assim, ela também se dedicaria à propagação e elevação da literatura em geral, discutindo assuntos e escritos sobre o tema. Na prática, isso se daria com a abertura de aulas de ensino teórico e haveria a previsão de publicação de periódico próprio, a

\footnotetext{
2 Ver Costa (2003), Andrade (2020), Levy (1977). No que diz respeito às dinâmicas do tráfico transatlântico de escravizados, sua abolição e reordenamentos posteriores à lei de 1850, ver Slenes (2005), Soares (2007), Rodrigues (2000); Marquese; Parron (2011) e Marquese; Salles (2016).

${ }^{3}$ Cf. Saba (2010). Para uma análise da aplicação do Código Comercial antes da aprovação da "Lei dos Entraves", ver Sonkajärvi (2015).
} 
interlocução com outras associações, fossem estrangeiras ou do Império, além da fundação de uma biblioteca (BRASIL, 1861, p. 386-387). Sobre os sócios, poderiam ingressar na Ensaios Literários brasileiros maiores de 16 anos, de conduta e ocupação honesta, e que pudessem arcar com uma joia no valor de $5 \$ 000$, mais mensalidades no valor de $2 \$ 000$.

Ainda neste mesmo ano de 1861, duas outras associações submeteram pedidos às vistas dos conselheiros, o Gabinete Português de Leitura e o Retiro Literário Português. Porém, não se tratava de procedimento para a fundação, e sim para a aprovação de alterações em seus regulamentos. Eram associações que, como consta no nome de ambas, destinavam-se exclusivamente aos súditos portugueses e mantiveram a restrição em vigor, tal qual quando foram fundadas, no final da década de 1830.4

Diante disso, é conveniente destacar que não foi ao acaso que a Ensaios Literários apontava, logo em seus artigos iniciais, a especificação de destinar-se a brasileiros, relacionando-se diretamente com restrições de perfil bastante comuns de outras sociedades literárias, baseadas na nacionalidade. Por outro lado, as três não deixavam de partilhar pontos importantes: todas tinham previsão de fundação de periódico próprio, da constituição de um acervo literário sobre áreas diversas, de manter correspondência com as demais sociedades de mesmo fim ou que fossem convenientes aos seus objetivos, além do compromisso etéreo da valorização das letras. ${ }^{5}$ Desse ponto em diante, diferenças voltavam à baila, e destaca-se o valor de $50 \$ 000$ de joia para associar-se ao Retiro Literário Português, dez vezes mais do que demandava a Ensaios Literários, além de mensalidade de 2\$000, antecipadas no valor do trimestre. Já o caso do Gabinete Português de Leitura chamava ainda mais atenção. Ele se organizou, ao menos como consta na sua nova versão estatutária, aos moldes de uma sociedade em comandita por ações, disponibilizando seu capital tal qual se vê no seu capítulo segundo:

\section{Capítulo II}

Do capital da sociedade, seus rendimentos e aplicação

Art. $3^{\circ} \mathrm{O}$ capital da Sociedade compõe-se:

$1^{\circ}$ Do produto de mil ações de $20 \$ 000$ cada uma, podendo emitir-se maior número quando o Conselho deliberativo o julgar conveniente

$2^{\circ}$ Da sexta parte do rendimento anual, que será capitalizada, e dos donativos feitos à Sociedade

$3^{\circ}$ Do excesso da renda no caso previsto no art. $7^{\circ}$

Art. $4^{\circ}$ Este capital é somente aplicável aos fins indicados nos número $1^{\circ}, 2^{\circ}$ e $4^{\circ}$ do $\operatorname{art.} 2^{\circ}$

Art. $5^{\circ}$ Os rendimentos da Sociedade consistem:

$1^{\circ} \mathrm{Nas}$ mensalidades pagas pelos acionistas

$2^{\circ}$ Nas quotas dos subscritores

$3^{\circ} \mathrm{Nas}$ multas impostas pelos Estatutos e regulamentos

$4^{\circ}$ No líquido das ações dos acionistas falecidos, cujos herdeiros, ou seus representantes, as não reclamarem no prazo de doze meses contados da data do aviso, que se fará por um ou mais periódicos

$5^{\circ}$ Em quaisquer outros rendimentos não classificados (BRASIL, 1861, p. 295)

\footnotetext{
${ }^{4}$ Ver Rozeaux (2016) e Gonçalves; Bessone (2016).

5 Para o estatuto do Gabinete Português de Leitura, cf. Brasil (1861, p. 295) e para o estatuto da sociedade Retiro Literário Português, cf. Brasil (1861, p. 498)
} 
Para que se tenha completa imagem do quadro, o artigo sétimo citado previa que, caso o capital da sociedade ultrapassasse 500\$000, o conselho deliberativo poderia manejar seu excedente, constituindo um fundo de reserva para ser capitalizado ou aplicado como suprimento de renda. Assim, tem-se que o valor do capital em ações declaradas pelo Gabinete Português de Leitura, para o ano de 1861, chegava a 20:000\$000 e ainda cabia aos acionistas pagar 3\$000 semestrais. Além disso, medidas de controle estavam estabelecidas para novos acionistas, que além da obrigatoriedade de serem cidadãos portugueses, bem morigerados, e de ocupação honesta, só poderiam tomar parte no capital societário requerendo à diretoria previamente, ou sendo diretamente indicados a ela por outro acionista.

De posse de uma estrutura capaz de produzir dividendos significativos, o Gabinete Português de Leitura previa ir além de apenas coligir obras para constituição de seu acervo e publicação de um periódico, estabelecendo previsão de ativamente imprimir manuscritos e reimprimir obras raras em língua portuguesa. Seguindo o mesmo caminho, o Retiro Literário Português deixava ainda mais clara suas aspirações editoriais:

Art.1 $1^{\circ}$ O Retiro Literário Português no Rio de Janeiro composto de súditos portugueses tem os seguintes fins.

$\int 1^{\circ}$ Animar sempre que possa a literatura pátria, dando a publicidade obras inéditas de abonado merecimento que sejam ofertadas à Sociedade, ou que lhe convenha ser delas editor, e enriquecer a nossa literatura, reimprimindo clássicos portugueses mais raros, e traduzindo de autores estrangeiros, obras muito raras principalmente em ciências, história, artes, poética e economia política (BRASIL, 1861, p. 498)

A possibilidade de publicar obras inéditas, coordenar traduções e reimpressões sugere um objetivo ambicioso do ponto de vista material para as duas associações, justificando o valor de joia e das ações, mesmo que não fique claro em seus estatutos se esses empreendimentos buscariam de fato ganhar as praças e disputar o comércio livreiro da cidade.

O mercado editorial no Brasil do Segundo Reinado possuía uma série de dificuldades e estava longe de se constituir como ambiente de fácil produção, edição e circulação de bens culturais impressos, dificuldades que incluíam oscilações no mercado externo e interno, custos com maquinário, importação de matérias-primas diversas e a concorrência com produtos manufaturados estrangeiros, incluindo livros. Assim, para compreender as possibilidades das sociedades literárias ao se enveredarem nos negócios da edição, alguns dados são importantes.

O estudo de Claudia Poncioni (2014) vem nesse sentido, ao tratar da circulação de ideias e impressos em Recife, especialmente a partir da chegada e difusão de livros franceses, ao final da década de 1840. Sendo o porto da cidade o primeiro entreposto a receber navios estrangeiros, por conta de sua localização geografia, ele tornava-se local privilegiado para observar fluxos e dados de importação. Para o objetivo específico que aqui mais importa, chama a atenção a pesquisa feita pela autora nos anúncios de livros franceses no Diario de Pernambuco e seus respectivos valores. Dessa maneira, em 1845, os livros anunciados variavam em seu valor de $120 \$$ a $1 \$ 220$. 
Para o ano de 1870, era possível encontrar no inventário da livraria de J. J. de Oliveira, localizada em Fortaleza, cinco exemplares da obra de Moreira de Azevedo utilizada no Colégio Pedro II, vendidas ao valor de $1 \$ 400$ cada (SILVA, 2017). Seguindo para o contexto da Corte, o catálogo da livraria do editor Francisco de Paula Brito, de 1858, é bastante significativo. Entre diversos impressos, havia obras avulsas que podiam chegar a $12 \$ 000$ e coleções que ultrapassavam em muito esse valor (GODOI, 2014). Já no que diz respeito diretamente aos custos de produção, algumas destas questões puderam ser observadas na desavença entre Paula Brito e a Sociedade Auxiliadora da Indústria Nacional, da qual era sócio.

O editor reclamava, em carta datada de 1854, dos valores que recebia pela impressão da revista da associação, o Auxiliador. A produção de mil exemplares vinha sendo feita ao custo de $150 \$ 000$, enquanto Paula Brito alegava receber pelo serviço o montante de $110 \$ 000$. Sobre a questão não houve acordo e a revista passou a ser impressa em outra tipografia. Essa pequena rusga deixa ver que as condições e custos da impressão no Brasil não eram das mais favoráveis, tanto que o renomado editor Baptiste-Louis Garnier, que dominou o comércio livreiro na Corte sobretudo a partir da década de 1860 (GRANJA, 2014), optava por imprimir suas obras em Paris, utilizando-se da estrutura das oficinas de seus irmãos editores, mas não raro também de outras tipografias da capital francesa. O processo de manter um leitor de provas em língua portuguesa na França, impressão e gastos com translado lhe eram menos onerosos do que executar tais processos no Brasil, especialmente após o surgimento dos navios a vapor, que encurtaram em muito o tempo da viagem transatlântica (HALLEWELL, 2012).

Nesse cenário, os trabalhadores das camadas médias do Rio de Janeiro devem ser trazidos à cena para ponderar tanto sobre as possibilidades de aquisição de bens culturais diversos, como sobre a possibilidade de inserção desses sujeitos em uma ou mais sociedades literárias do período. Assim, a tabela dos vencimentos dos empregados da Secretária de Estado dos Negócios da Agricultura, Comércio e Obras Públicas pode trazer alguma compreensão. Para ano de 1868, tem-se que as ocupações de ajudante, contínuo e correios recebiam ordenado mensal de 1:000\$000, mais gratificações que variavam entre os valores de $400 \$ 000$ e $600 \$ 000$. Já os praticantes, que eram no total de seis funcionários dentro dessa secretaria, não recebiam ordenado, apenas gratificações no valor de $960 \$ 000$. Quando se tratava dos postos mais altos, há um aumento expressivo: o diretor da secretaria recebia ordenado de 5:000\$000 mais gratificação mensal de 2:192\$422. Os chefes de seção, que eram no total de cinco, percebiam o ordenado de 4:000\$000 e gratificação mensal no valor de 994\$736 (BRASIL, 1868, p. 295). Desse modo, o conjunto desses dados apresentados - da precificação de livros em meados da década de 1840 até a tabela de vencimentos nas imediações do ano de 1870 - fornecem balizas para afirmar que as classes médias letradas daquelas décadas tinham possibilidade de, em maior ou menor medida, estabeleceremse como consumidores constantes do mercado livreiro. É possível considerar também que possuíam condições financeiras de arcar com joias e mensalidades de mais de uma associação, sugerindo que 
pudessem tomar parte em diversas delas de forma simultânea, a depender de seus interesses, alimentando a rede do associativismo literário no Rio de Janeiro. ${ }^{6}$

Assim, é importante demarcar que se as sociedades determinavam o perfil de seus sócios por critérios censitários, de nacionalidade, de ofício ou de idade, elas também usavam parâmetros menos evidentes, que acabavam por incidir sobre gênero, raça e classe social. Era o caso das vagas concepções já mencionadas de honestidade, ser bem morigerado, ter emprego respeitável, boa conduta. Além disso, não há dúvidas que o letramento impunha pré-requisito quando se trata do associativismo literário, o que importa especialmente diante das altas taxas de analfabetismo na Corte, na casa dos 70\% para o Município Neutro do Rio de Janeiro. Portanto, não é menos importante anotar que, para meados do XIX, trabalhadores manuais de baixa qualificação tinham renda entre $150 \$ 000$ e $200 \$ 000$ anuais (LOBO, CARNAVARROS, ELIAS et al, 1973). Também estavam inclusos nesse espectro homens e mulheres escravizados, exercendo a função de escravos de ganho.

Diante desse cenário, é revelador que a sociedade Ensaios Literários se fizesse um tanto mais acessível do ponto de vista econômico, na medida que se voltava principalmente para o estímulo à formação intelectual geral de seus sócios. A previsão de ofertar cursos diversos, o acesso exclusivo a brasileiros e a dedicação em promover debates literários e eventuais produções, a serem publicadas apenas em seu periódico, revelavam pretensões menos onerosas e mais circunscritas. Esse perfil também sugeria que seus integrantes pudessem vir de substratos mais baixos das classes médias da Corte, em comparação às sociedades portuguesas tratadas até aqui. De todo modo, as três associações traziam em seus estatutos respostas a questões sensíveis do mundo das letras, permitindo, portanto, certo mapeamento de lacunas e nichos de ação. A partir de seus objetivos e articulações, salta ao primeiro plano o foco nas formas privadas de acesso à instrução, à atividade editorial e à composição de acervos científicos e literários. As consequências possíveis dessas iniciativas apontam, ainda, para a criação de comunidades conectadas de leitores e escritores, necessariamente ligadas à veiculação de periódicos próprios, o que fomentava o espaço da imprensa e o crescimento do mercado editorial no Segundo Reinado.

O conjunto dessas questões atravessou muitas das associações no curso do tempo, fomentando e renovando constantemente esse ecossistema das letras com o surgimento e desaparecimento de sociedades em ritmo notável, o que é possível de ser percebido tanto na historiografia (PEREIRA, 2015) como na atividade do Conselho de Estado, até o início da década de 1880. É importante ressalvar, entretanto, que não há dúvidas que escapam a essa análise as sociedades que tiveram seus estatutos rejeitados, que não obtiveram decretos de autorização de funcionamento e, portanto, não compuseram o escopo documental aqui tratado. Ainda assim, não deixa de ser significativo observar que as que conseguiram chancela imperial deixassem às vistas parte dos sentidos e funcionamentos desejados pela

\footnotetext{
${ }^{6}$ De acordo com o censo de 1872, a taxa média de alfabetização no Brasil era de 14\%. Esses dados variam quando observados regionalmente e, para São Paulo, tem-se uma taxa de 17\%, enquanto para o Município Neutro, o Rio de Janeiro, a taxa de alfabetização chegava a 30\%. Cf. Rosso (2010)
} 
institucionalidade. Assim, quando o Instituto Polimático Brasileiro teve seus estatutos aprovado em 1862, novos aspectos foram trazidos à baila.

Entre as décadas de 1860 e 1870, o Instituto Polimático Brasileiro declarou intenção de se debruçar sobre o exercício profissional dos homens de letras. Em seu artigo primeiro, havia especificação de que se destinava a cidadãos brasileiros, impondo restrição às demais nacionalidades - estrangeiros seriam aceitos apenas na categoria de honorários ou beneméritos. A seguir, afirmava-se a necessidade de reconhecida boa conduta e, por fim, deveriam ser "Doutores, Licenciados ou Bacharéis formados em qualquer das Faculdades Científicas conhecidas, ou que se dediquem ao curso d'elas, do comércio, das letras e belas artes" (BRASIL, 1862, p. 5). A posse de diploma, ou dedicação reconhecida nas áreas acima, seriam o caráter definidor do Instituto, sendo absolutamente bem-vindo que diversos domínios do conhecimento circulassem dentro da associação, como o próprio significado de "polimático" deixa explicitar. A partir disso, apresentavam-se seus objetivos:

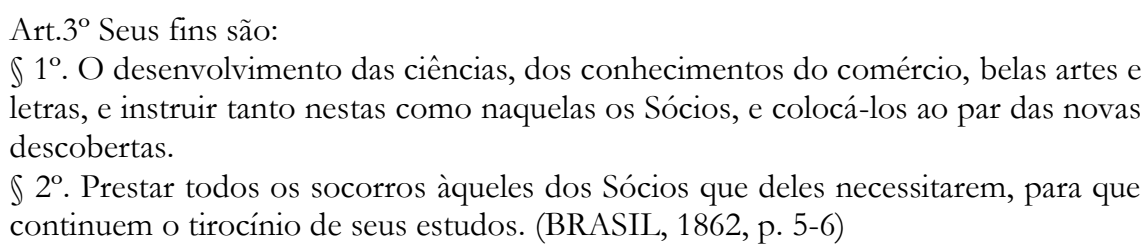

Além desses dois itens, determinava-se comemorar o aniversário da Independência do Brasil, corresponder-se com sociedades científicas "de todos os países cultos", assinar periódicos nacionais e estrangeiros, além de criar uma biblioteca, quando houvesse fundos para tanto.

É interessante destacar que havia uma previsão original no estatuto do Polimático, se comparado às sociedades citadas anteriormente. Ela apontava para novas demandas sociais, mesmo que permanecessem os fins gerais de engrandecimento das letras e estímulo intelectual dos associados. De posse de seus títulos e a partir deles congregados num campo comum de partilha, emergia a iniciativa de prestação de socorros mútuos. Ela não ficou detalhada nas normas analisadas pelo Conselho de Estado e nem por ele foi determinado que ficasse, visto que os estatutos foram aprovados sem pedidos de alteração. Entretanto, havia ao menos a indicação de que o auxílio viesse a quem precisasse de apoio para dar continuidade aos seus estudos, garantindo assim a manutenção de uma das condições de ingresso e permanência dos sócios no Instituto Polimático Brasileiro. Do ponto de vista da contribuição financeira, a joia para ingresso tinha valor de $6 \$ 000$ e as mensalidades no valor de $1 \$ 000$. A associação ainda promoveria frentes específicas de formação, como revelavam as seções sob as quais parte dos trabalhos se davam: Direito, Direito Canônico, Comércio e Indústria, Literatura e Belas Artes (BRASIL, 1862, p. 6).

Tais aspectos podem ser vistos também em outra associação, o Instituto dos Bacharéis em Letras, fundado em 1864. Nele acenava-se para a mesma perspectiva de valorização das letras e formação dos sócios, e avançava ainda mais em direção à questão dos socorros mútuos, prevendo a criação de uma caixa de beneficência (BRASIL, 1868, p. 83). As categorias que compunham a associação variavam entre 
integrantes honorários, beneméritos, benfeitores, além de correspondentes e efetivos, um padrão bastante recorrente de organização. Apenas aos dois primeiros grupos não se exigia necessidade do diploma de bacharel, e aos dois últimos ele era obrigatório. Especificamente para os sócios efetivos, ainda se exigia pagamento de joia de $50 \$ 000$, mensalidade de $2 \$ 000$ e a defesa de uma memória sobre qualquer parte de estudos desenvolvidos no Imperial Colégio Pedro II.

Vê-se, ademais, que o valor da joia era bastante elevado tendo em vista algumas das sociedades já analisadas do período, o que sugestionava empreendimentos mais onerosos. Diante disso, a previsão de criação de uma caixa de beneficência pode indicar destino para parte desses recursos, ainda que constem poucos detalhes sobre isso no estatuto: apenas o plano de constitui-la. Junto a ele, descreviamse as obrigações do tesoureiro de indicar casa bancária de confiança, para depósito dos fundos gerais, bem como dos fundos especiais, da caixa, que por ele deveria ser administrada.

Tanto o Instituto dos Bacharéis como o Instituto Polimático testavam formas associativas capazes de promover qualificação e, principalmente, direcionadas a sujeitos integrantes de um mesmo campo de atuação profissional (BRASIL, 1868, p. 91). Foi a partir desse aspecto aglutinador que ambas as sociedades avançaram para se dedicar à seguridade de seus sócios. Assim, se por um lado a ideia de valorização das letras, das ciências e da língua pátria tivessem servido de substrato para a criação de diversas associações, desde o final do século XVIII, por outro, voltar-se para critérios relacionados à reprodução da vida material, custeio de estudos e outras demandas de socorro emergiam cada vez mais, atreladas ao novo cenário de fundação das sociedades beneficentes naquela conjuntura.

Vê-se, pois, que tal movimento não passou ao largo das sociedades literárias e diante disso, ainda que bacharéis, doutores ou licenciados não constituíssem um grupo profissional com contornos explícitos, critérios foram estabelecidos para tentar dar mínima forma ao corpo dessas associações. Então, diplomas e fluência reconhecida pelos pares em determinadas áreas criavam o amálgama possível, aproximando-os em suas práticas de ofício, em seus locais prováveis de trabalho, e possivelmente no compartilhamento de círculos sociais fora da associação - fatores esses que acabavam por indicar uma série de condições essenciais à análise das sociedades. O pagamento de joia no valor de $50 \$ 000$ era um deles.

Diante desse amplo terreno, no qual se posicionavam sociedades diversas, pode-se indicar que havia algumas formas principais de associativismo literário, que atravessaram a década de 1860 e se mantiveram nos anos posteriores. Dentro do espectro da valorização das letras, na qual todas tomavam ponto de partida, havia as sociedades que se dedicavam à instrução geral nas áreas da literatura e das ciências, as sociedades que acabaram por concentrar esforços na formação de acervo literário e edição de obras, e sociedades de caráter mais profissional, direcionadas para aprimoramento técnico-científico de seus participantes, algumas com mecanismos de seguridade social. Esses três modos de se associar, vale ressaltar, poderiam estar presentes na mesma sociedade, variando em importância, mas o conjunto dessas iniciativas demarcava a dinâmica ascendente do universo letrado da Corte. Especialmente, quando 
se olha para o campo dos impressos e para as sociedades voltadas à instrução, esse contexto fica mais claro.

O exemplo do Retiro Literário Português volta a se fazer significativo, visto que submeteu seus estatutos para serem avaliados pelo Conselho de Estado, no ano de 1870, após alterações. Ele foi aprovado com apenas um adendo e a nova redação mostrava uma mudança bastante clara de perfil. Enquanto na versão do ano 1861 seu primeiro dispositivo dizia do objetivo de editar, imprimir e reimprimir obras, além de realizar traduções, para a versão de 1870 tinha-se, nesse mesmo lugar, a seguinte redação:

Art. $1^{\circ} \mathrm{O}$ Retiro Literário Português no Rio de Janeiro é composto de portugueses natos ou por adoção, maiores de 16 anos, de honesta ocupação e reconhecida moralidade; e tem por fins;

$\$ 1^{\circ}$. Animar por todos os meios ao seu alcance a literatura pátria e promover a instrução instituindo para isso cursos de retórica, história, geografia, filosofia e comércio; das línguas latina, portuguesa, francesa e inglesa e as mais que as circunstâncias da sociedade permitirem; podendo a diretoria instituir de preferência as que julgar mais necessárias. Pela imprensa será convidados os professores que pretenderem as cadeiras de ensino a mandarem à diretoria as suas propostas admitindo ela (sic) depois os que julgar. Os professores de línguas que a diretoria houver de admitir deverão ser competentemente habilitados pela instrução pública. (BRASIL, 1870, p.33)

Essas pretensões, agora em destaque logo de início, não estavam ausentes do estatuto anterior, mas se encontravam de maneira mais sintética e apenas no parágrafo quarto desse mesmo artigo. Por outro lado, as atividades editoriais que antes ocupavam o destaque da abertura foram, de fato, suprimidas da nova versão. As justificativas para tal poderiam ir de problemas financeiros, impossibilidades logísticas de concretizar tal empresa, ou a tentativa de ampliar o número de sócios, voltando-se para o campo da instrução e não mais para ramo da impressão e editoração. As alterações nos valores de joia e mensalidade também apontam para uma tentativa de popularização. O comparativo é interessante: em 1861 cobravase $50 \$ 000$ e $2 \$ 000$ respectivamente, já em 1870 cobrava-se $10 \$ 000$ e $1 \$ 000$ respectivamente dos sócios.

Se o Retiro Literário Português indicava mudança em seu perfil de atuação, deixando de lado as atividades editoriais, outras iniciativas surgiam no ramo. Era o caso da Associação Nacional TipográficoLiterária, de 1873, que tinha por objetivo publicar obras originais de autores brasileiros, através da compra e venda de manuscritos. Ela estabelecia sua atuação sobre o conjunto das atividades do comércio de livraria, tipografia, litografia, xilogravura e autografia (BRASIL, 1870, p. 915). Se tratava de uma sociedade com capital de 500:000\$000, divididos em 10 mil ações no valor de 50\$000, e se não é possível tomá-la como uma sociedade literária nos moldes apresentados até aqui, ela é importante para trazer às vistas o montante de investimentos supostos para atuar no mercado dos impressos daqueles anos.

Como se vê, os valores estavam em patamares muito acima do que dispunha o Retiro Literário Português, mas era um mercado promissor à década de 1870, caso houvesse recursos disponíveis para tanto (Cf. GRANJA, 2016; GRANJA, 2013; MOLLIER, 2011; e ABREU; BRAGANÇA, 2010). Outro ponto destacável está no fato de que a Associação Nacional Tipográfico-Literária estabelecia em seus 
estatutos a finalidade de espalhar a instrução ao povo por meio da leitura, portanto, afirmava que poderia criar uma folha de caráter literário, científico, político e industrial. A iniciativa seria viabilizada assim que a diretoria encontrasse as formas menos custosas para a sociedade. O periódico deveria priorizar a difusão do conhecimento da Geografia e História do Brasil.

A Associação Nacional Tipográfico-Literária não estava sozinha nesse movimento, vale lembrar. Anos antes, em 1871, havia surgido na capital da província do Pará, Belém, a Empresa Tipográfica e Jornalística, que funcionava aos moldes de uma sociedade comanditária com capital anunciado de 100:000\$000, divididos em 50 ações de 2:000\$000, o que de pronto revela seu caráter mais restrito reafirmado em dispositivos estatutários (BRASIL, 1871, p. 552). Desse modo, com base nesse quadro, essas dinâmicas devem ser inseridas como parte constitutiva do próprio funcionamento e expansão do mercado das letras, já nas imediações do último quartel do século XIX. É importante destacar, inclusive, que o modelo de sociedade que se centrava exclusivamente em constituir acervos, como a Associação Literária British Subscrption Library, de 1863 (BRASIL, 1863, p. 317), parece ter perdido força. As razões para isso podem estar inseridas dentro desse amplo processo de aquecimento do mercado editorial, que proporcionava crescente estruturação e circulação de impressos sobretudo na Corte, aumentando a possibilidade de aquisição individual de livros e periódicos.

No mesmo caminho, a imprensa também teve seu impulso, visto que estava intimamente ligada à atividade das associações e ao campo das ciências e das letras, além de tomar parte significativa no ramo da tipografia, constituindo, não raro, oficinas próprias. Dessa forma, os empregados das folhas viram a possibilidade de fundar mutuais em compasso com a expansão dos jornais, não deixando de constituir suas organizações. A primeira mutual que reuniu o conjunto dos trabalhadores de um mesmo periódico surgiu no início da década de 1880: a Sociedade Beneficente dos Empregados da Gazeta de Notícias. ${ }^{7}$ Já no ramo dos trabalhadores das tipografias, merece destaque a Associação de Auxílios Mútuos dos Empregados da Tipografia Nacional, herdeira de uma importante tradição associativa que remontava à década de 1850, quando ocorreu, inclusive, a greve dos compositores tipógrafos, de 1858 (VITORINO, 2000; VITORINO, 1999).

Ambas as experiências são importantes de serem trazidas porque compõem os elementos desse ecossistema das letras, das associações, das oficinas, da circulação dos impressos que aqui tem sido analisado. A Gazeta de Notícias foi uma folha diária de absoluta importância para o desenvolvimento da imprensa e dos modos de se fazer jornalismo no Brasil, desde o momento que ganhou as prensas e as ruas do Rio de Janeiro, em agosto de 1875, convertendo-se numa verdadeira empresa jornalística entre as décadas de 1880 e 1890. Foi nesse contexto que os empregados da Gazeta de Notícias fundaram sua associação.

Para o outro caso mencionado, o da associação dos empregados da Tipografia Nacional, uma reflexão um pouco mais detida pode vir a calhar, porque os seus estatutos deixam ver a dimensão da

\footnotetext{
${ }^{7}$ Em 1868, havia sido fundada a Associação Beneficente dos Compositores do Jornal do Comércio, que, como indica o nome, se referia apenas a uma parte dos trabalhadores do diário.
} 
organização e extensão do que se tornou a antiga Impressão Régia. Em seu artigo 44 (BRASIL, 1880, p. 393) indicava-se que a mutual foi fundada por ação de seu administrador, mas teria sido instituída "por todos os operários e empregados da mesma tipografia e do Diário Oficial, que o quiserem, admitidos ou nomeados pelo Administrador" (BRASIL, 1880, p. 385). Dentre muitos aspectos, o que mais se destacava era sua estrutura de funcionamento, comportando os mais diversos níveis de trabalhadores, evidenciados através da descrição do sistema de representação e eleição de delegados descrito nas normas.

A assembleia geral da associação seria formada por cinco representantes de cada oficina existente da Tipografia Nacional e de cada nova oficina que se criasse. Os empregados avulsos, que não pertencessem a nenhuma oficina, deveriam se reunir aos empregados de escritório, revisores e conferentes para também eleger cinco delegados. Da mesma maneira, a turma formada pelos empregados das máquinas de impressão do Diário Oficial deveria se juntar aos empregados da remessa, aos entregadores das folhas e aos serventes para eleger seus cinco representantes. Também tinham esse direito os empregados nomeados pelo governo, artistas nacionais ou estrangeiros contratados, além dos oficiais obreiros. Caberia a esse grupo eleger seus delegados e ficava-lhes facultado o direito de fixar as cotas para contribuir com o fundo social, devido à possível sazonalidade de seus trabalhos. Tal arranjo deixa ver os detalhes da cadeia produtiva da Tipografia Nacional e os meios nos quais se ocupavam seus diversos empregados. Como consequência, tem-se dimensão da amplitude das funções que engendrava uma tipografia de grande porte dentro do mercado das letras no período e a quantidade de engrenagens movimentadas, do ponto de vista econômico, social, político e cultural.

Dessa maneira, ambas as mutuais devem ser entendidas dentro do andamento da ampliação da atividade editorial, da circulação de periódicos, da expansão e especialização do trabalho intelectual, da ampliação gradativa da instrução, todas reveladas na história das associações literárias e dos trabalhadores do mundo das letras.

\section{CONCLUSÃO}

O associativismo foi parte constitutiva das inúmeras atividades que compuseram o universo literário do Rio de Janeiro, durante o século XIX, sobretudo na sua segunda metade. Através das inúmeras sociedades que foram efetivamente fundadas, e também daquelas que buscaram se organizar mas que não chegaram a entrar em funcionamento, um efervescente ecossistema se constituiu por meio da configuração de redes de periódicos e circulação de impressos, da comunicação entre entidades nacionais e estrangeiras, e da circulação de pessoas pelas conferências, cafés e sedes de associações. Portanto, para o contexto da Corte, salpicada dessas iniciativas que não raro tiveram curta duração, não é possível negligenciar que tenham cumprido papel importante na expansão das atividades literárias, editoriais e jornalísticas. 
Dessa maneira, esse artigo buscou perseguir as formas como se organizaram as sociedades de caráter literário a partir da década de 1860, observando os temas aos quais se dedicavam, as atividades que encampavam e seus objetivos. Através desse percurso, foi possível perceber que elas ocuparam posição importante no ascendente cenário cultural da cidade do Rio de Janeiro como criadoras de conexões, possibilidades de ação e local de exercício do trabalho intelectual em áreas diversas - da instrução à editoração de livros, passando pela imprensa e pelo ofício de escrever. Assim e por fim, considera-se aqui que o associativismo literário que perpassou os meados do século XIX foi fundamental para a constituição do dinâmico mundo das letras do fim dos oitocentos e início dos novecentos.

\section{REFERENCIAS}

ABREU, M.; BRAGANÇA, A. (org.). Impresso no Brasil: dois séculos de livros brasileiros. São Paulo: Ed. da UNESP, 2010.

ANDRADE, L. B. de. Negociantes e capitalistas: transformações das práticas mercantis no Brasil imperial, em meados do século XIX, Ouro Preto, Minas Gerais. América Latina en la bistoria economica, México, v. 27, n.1, e1015, p.1-22, jan.-abr 2020.

AZEVEDO, M. D. M. de. Sociedades fundadas no Brasil desde os tempos coloniais até o começo do atual reinado. Revista do Instituto Histórico e Geográfico Brasileiro, Rio de Janeiro, IHGB, t. 48, v. 71, pt. 2, p. 265-322, 1885.

BATALHA, C. H. de M. Sociedades de trabalhadores no Rio de Janeiro do século XIX: algumas reflexões em torno da formação da classe operária. Cadernos AEL, Campinas, v. 6, n. 10-11, , p. 44-66, 1999.

BATALHA, C. H. de M. Formação da classe operária e projetos de identidade coletiva. In: FERREIRA, J., NEVES, L. de A N. D (org.). O Brasil Republicano: o tempo do liberalismo excludente, v.1, Rio de Janeiro: Civilização Brasileira, 2003. p.163-187

BATALHA, C. H. de M. Relançando o debate sobre mutualismo no Brasil: as relações entre corporações, irmandades, sociedades mutualistas de trabalhadores e sindicatos à luz da produção recente. Revista Mundos do Trabalho, Florianópolis, v.2, n. 4, p.12-22, ago.-dez, 2010.

BRASIL. Coleção das leis do Império do Brasil de 1861, Tomo XXIV, Parte II, Rio de Janeiro: Tipografia Nacional, 1861.

BRASIL. Coleção das leis do Império do Brasil de 1863, Tomo XXIV, Parte II, Rio de Janeiro: Tipografia Nacional, 1863.

BRASIL. Coleção das leis do Império do Brasil de 1868, Tomo XXXI, Parte II, Rio de Janeiro: Tipografia Nacional, 1868.

BRASIL. Coleção das leis do Império do Brasil de 1870, Tomo XXXIII, Parte II, Rio de Janeiro: Tipografia Nacional, 1870.

BRASIL. Coleção das leis do Império do Brasil de 1871, Tomo XXXIV, Parte II, Rio de Janeiro: Tipografia Nacional, 1871. 
BRASIL. Coleção das leis do Império do Brasil de 1880, Tomo XLIII, Parte II, Rio de Janeiro: Tipografia Nacional, 1880.

COSTA, W. P. Estratégias ladinas: o imposto sobre o comércio de escravos e a "legalização" do tráfico no Brasil (1831-1850). Novos Estudos CEBRAP, São Paulo, n. 67, p. 57-75, nov. 2003,

GAMBI, T. F. R. A centralização política e o desenvolvimento financeiro no Brasil Império (1853-66). Varia História, Belo Horizonte, v. 28, n. 48, p. 805-832, jul.-dez. 2012.

GODOI, R. C. de. Um editor no Império: Francisco de Paula Brito (1809-1861). Tese (Doutorado em História) - Universidade Estadual de Campinas, Campinas, 2014.

GONÇALVES, M. de S.; BESSONE, T. O Real Gabinete Português de Leitura do Rio de Janeiro: um espaço para a ciência médica Oitocentista. Almanack, Guarulhos, n. 14, p. 264-296, set.-dez. 2016.

GRANJA, L. Rio-Paris: primórdios da publicação da Literatura Brasileira chez Garnier'. Revista Letras, Santa Maria, v. 47, p. 81-95, 2013.

GRANJA, L. Garnier no Brasil: esta história se faz com homens e livros. ABREU, M.; DEACTO, M. M. (org.). Circulação transatlântica dos impressos - conexões. Campinas: Unicamp/IEL/Setor de publicações, 2014. p. 33-42.

GRANJA, L. Um editor no espaço público: Baptiste-Louis Garnier e a consolidação da coleção em Literatura Brasileira. Estudos Linguísticos, São Paulo, v. 45, n. 3, p.1205-1216, 2016.

HALLEWELL, L. O Livro no Brasil: sua história. São Paulo: Edusp, 2012.

JESUS, R. P. Associativismo no Brasil do Século XIX: repertório crítico nos registros de sociedades no Conselho de Estado (1860-1889). Locus,. Juiz de Fora, v.13, n.1, p.144-170, 2007.

JESUS, R. P. de, LACERDA, D. P. Dinâmica associativa no século XIX: socorro mútuo e solidariedade entre livres e libertos no Rio de Janeiro Imperial. Revista Mundos do Trabalho, Florianópolis, v. 2, n. 4, p.126-142, ago.-dez. 2010.

LACERDA, D. P. Solidariedade entre ofícios: a experiência mutualista no Rio de Janeiro Imperial (18601882), Dissertação (Mestrado em História) - Universidade Estadual de Campinas, Campinas, 2011.

LEVY, M. B. História da Bolsa de Valores do Rio de Janeiro. Rio de Janeiro: IBMEC, 1977.

LEVY, M. B. A indústria do Rio de Janeiro através de suas sociedades anônimas. Rio de Janeiro: Ed. da UFRJ; Secretaria Municipal de Cultura do Rio de Janeiro, 1994.

LOBO, E. M. H.; CARNAVARROS, O.; ELIAS, Z. F. et al. Estudos das categorias socioprofissionais, dos salários e do custo da alimentação no Rio de Janeiro de 1820 a 1930. Revista Brasileira de Economia. Rio de Janeiro, v. 27, n. 4, p. 129-176, 1973.

LUCA, T. R. de. O Sonho do futuro assegurado: o mutualismo em São Paulo. São Paulo: Contexto, 1990.

MAROTTA, M. C. As sociedades do Império: política, economia e associativismo beneficente no Rio de Janeiro do Segundo Reinado, Dissertação (Mestrado em História) - Universidade Federal Fluminense, Niterói, 2015.

MARQUESE, R. de B.; PARRON, T. P. Internacional escravista: a política da Segunda Escravidão. Topoi, Rio de Janeiro, v. 12, n. 23, p. 97-117, 2011. 
MARQUESE, R. de B; SALLES, R. A escravidão no Brasil oitocentista: história e historiografia. In: MARQUESE, R. de B.; SALLES, R. (org.), Escravidão e Capitalismo histórico no século XIX: Cuba, Brasil e Estados Unidos. Rio de Janeiro: Civilização Brasileira, 2016. p.110-179.

MOLLIER, J. A História do Livro, da Edição e da Leitura: um balanço de 50 anos de trabalho. In: I SEMINÁRIO BRASILEIRO SOBRE O LIVRO E A HISTÓRIA EDITORIAL. Anais... Rio de Janeiro, Casa Rui Barbosa, de 08/11 a 11/11 de 2011. Disponível em: http://www.livroehistoriaeditorial.pro.br/Mollier\%201.pdf.

PEREIRA, M. da. S. A crítica que fez história: as associações literárias no Oitocentos. São Paulo: Ed. da Unesp, 2015.

PONCIONI, C. Trajetos de livros, técnicas e ideias: França - Brasil (1840 e 1846). In: ABREU, M.; DEACTO, M. M. (org). A circulação transatlântica dos impressos: conexões. Campinas: UNICAMP/IEL/Setor de Publicações, 2014, p. 25-32.

RODRIGUES, J. O infame comércio: propostas e experiências no final do tráfico de africanos para o Brasil (1800-1850). Campinas: Ed. da Unicamp, 2000.

ROSSO, S. D. Condições estruturais de emergência do associativismo e sindicalismo no setor de educação. Leitura a partir de dados censitários brasileiros. In: II SEMINÁRIO INTERNACIONAL DA REDE DE PESQUISADORES SOBRE ASSOCIATIVISMO E SINDICALISMO DOS TRABALHADORES EM EDUCAÇÃO. Anais... Rio de Janeiro, 22 e 23 de abril de 2010. Disponível em: https://redeaste.irice-conicet.gov.ar/sites/default/files/Rosso1.pdf. Acessado em: 30 set. 2020

ROZEAUX, S. Presença da "colônia portuguesa" na paisagem cultural e midiática do Rio de Janeiro: o Grêmio Literário Português e o Retiro Literário Português (1855-1885). Topoi, Rio de Janeiro, v. 17, n. 33, p. 490-513, jul.-dez 2016.

SABA, R. N. P. F. As praças comerciais do Império e a aprovação do Código Comercial Brasileiro na Câmara dos Deputados. Angelus Novus, São Paulo, n.1, p. 77-96, agosto 2010.

SÁENZ, H. E. L. A evasão de ouro dos fundos bancários em meados do século XIX e suas consequências para a política econômica. Almanack, Guarulhos, n. 1, p. 66-87, 1º sem. 2011.

SLENES, R. W. The Brazilian Internal Slave Trade, 1850-1888: Regional Economies, Slave Experience and the Politics of a Peculiar Market. In JOHNSON, W (org.). The Chattel Principle: Internal Slave Trades in the Americas. New Haven: Yale University Press, 2005, p. 325-370.

SILVA, O. de A. A publicidade livresca em jornais do século XIX: anúncios, livros e estratégias de venda. In: INTERCOM: XIX Congresso de Ciências da Comunicação da Região Nordeste. Anais... Fortaleza, 29 de junho a 01 de julho de 2017. Disponível em: https://www.portalintercom.org.br/anais/nordeste2017/resumos/R57-1851-1.pdf. Acessado em: 30 set. 2020 .

SOARES, L. C. "O povo de Cam” na capital do Brasil: escravidão urbana no Rio de Janeiro do século XIX,. Rio de Janeiro: FAPERJ; 7 Letras, 2007

SONKAJÄRVI, H. A aplicação do Código Comercial brasileiro entre 1850 e 1860: análise das evidências de um caso de falência. Tempo, Niterói, v. 21, n. 37, p.170-186, jul. 2015.

VISCARDI, C. M. Experiências da prática associativa no Brasil (1860-1880). Topoi, Rio de Janeiro, v. 9, n.16, p. 117-136, jan.-jun. 2008. 
VISCARDI, C. M. Estratégias de sobrevivência: o mutualismo no Rio de Janeiro Republicano. Revista Brasileira de História, São Paulo, v.29, n. 58, p. 291-315, 2009.

VITORINO, A. J. R. Escravismo, proletários e a greve dos compositores tipográficos de 1858 no Rio de Janeiro. Cadernos AEL, v. 6, n. 10/11, p.70-108, 1999.

VITORINO, A. J. R. Operários e Máquinas: mudança técnica e sindicalismo gráfico (São Paulo e Rio de Janeiro 1859-1929). São Paulo: Annablume, 2000.

Data de submissão: 30/09/2020

Data de aprovação: 17/11/2020 